\title{
The ELT Preparatory Class Students' Strategy Using Profiles and Attitudes towards Foreign Language Learning: Amasya University Sample
}

\author{
Ayfer SU BERGIL * \\ English Language Teaching Department, Amasya University, Amasya,Turkey \\ Arif SARIÇOBAN \\ English Language Teaching Department, Hacettepe University, Ankara, Turkey
}

\begin{abstract}
The unsatisfactory language performance of L2 is among very common complaints voiced by the language teachers and educators for many years. These complaints push the applied researchers in the field of learning and teaching L2 searching for the causes of these kinds of problems and offering recommendations for solutions. Therefore, the need for this attempt dates back to the early years of 1970s as the majority of the research focused on developing the teaching methods and instructional materials. Parallel to the great efforts to understand the nature of the learning and teaching, since the early years of 1970s, great emphasis has been placed on social, psychological and affective factors that enhance or inhibit L2 success and achievement. Motivation, personality, learning style is among these variables that sound important places in different research. Taking a further step, this research aims to investigate the role of strategies and attitudes in L2 learning and teaching settings where English language has a role of foreign language as well. For this purpose, this research seeks the answers of what strategies the ELT preparatory class student use, whether the students' achievement differs according to the strategy they use or not, what the students' attitudes towards foreign language learning are, whether the students' achievement differs according to the attitudes towards foreign language learning and there is a meaningful relation between the students' strategy using profiles and attitudes towards foreign language learning or not. 22 Amasya University ELT preparatory class students, enrolling in 2014- 2015 academic year, consist the scope of this research. The data provide basis for this research have been collected via two different data collection instruments which are labelled as SILL (Strategy Inventory for Language Learning) and a questionnaire on attitudes towards learning a foreign language. The strategy inventory for Language Learning (SILL) is for the students of a second language developed by Oxford (1990). This inventory consists of 5 parts aimed to define the students strategy profiles in terms of remembering more effectively, using all mental process, compensating for missing, organizing and evaluating, managing emotions, learning with others. The inventory comprises 50 items each of which is labelled with the options that range from " $1=$ Never or almost never true for me", " $2=$ Usually not true of me", " $3=$ Somewhat true of me", " $4=$ Usually true of me" and " $5=$ Always or almost always true of me". The questionnaire on attitudes towards foreign language learning was adopted by Tunçok (2010) from Horwitz's (1988) Beliefs About
\end{abstract}

*Assistant Professor Doctor, ayfersubergil@ amasya.edu.tr 
Language Learning Inventory (BALLI) and the Attitude/ Motivation Test Battery (AMTB) by Gardner (1985) adding eight more items. The questionnaire consists of 31 items and the answers are labelled as 7 point likert-type format sequencing from 1(totally disagree) to 7 (totally agree). In the study, both qualitative and quantitative research methods were applied together. For the data analysis of this study, SPSS 17.00 package program for social sciences was used throughout the whole process. According to the findings, this research shares the information and insight that learners' strategy using profiles and attitudes towards foreign language learning should be kept in mind during the applications of all classroom activities especially in the foreign language learning settings. Moreover, the findings have significant implications for research on classroom instruction, material design and teacher education as well.

Key Words: Language learning, strategies, attitudes, foreign language learning and teaching

\section{Introduction}

Since multilingualism has become more than just important in today's era, knowing a foreign language apart from the native language has evolved to be extremely beneficial. No matter viewed from different aspects, being able to communicate in a foreign language helps people to make real connection and provides understanding of yourself and your native language as well. The importance of a foreign language opened up new avenues in making learning and teaching it more meaningfully and easily in last decades of this century. That's why language learning and teaching experienced a long way from methodological instructions to the activity or task based beliefs and refers nowadays the post-methodological aspects of a language which serves as a benchmarking term for a foreign language learning pedagogy. By this way, individual differences, motivations, preferences and needs emphasized more heavily. Moreover, the theories and methods are tried to be supported by the samples or practices of these individualized facts that motivate the learners at different degrees throughout their language learning process. As a result, this study aims to investigate the strategies that foreign language learners use in their learning process and the foreign language learners' attitudes towards this process in an individualized point of view.

\section{Language Learning Strategies}

Learning strategies are based on the students' needs to enhance their own learning. Therefore, the strategies are accepted important especially for language learning because they are such kinds of tools that help learners to develop communicative competence by leading the learners to active, self-directed involvement. Throughout history, it has been observed that the best language students have used strategies ranging from naturalistic language practice techniques to analytic, rule-based strategies. Nowadays, language learning strategies are becoming widely recognized in educational practices. Under various names such as learning skills, learning to learn skills, thinking skills, and problem solving skills; learning strategies are the way students learn in a wide range of opportunity. Moreover, it is known that these learning strategies also refer to the terms of learning and acquisition, process orientation, four language skills, second and foreign language, communication, communicative competence. At this point, it can be referred that language learning strategies contribute to the main goal of communicative competence, allow learners to become more self-directed, expand the role of teachers, are problem-oriented and specific actions taken by the learner, involve many aspects of the learner not just the cognitive, support learning both directly and indirectly, are not 
always observable and often conscious, can be taught, they are both flexible and influenced by a variety of factors. Generally, learning strategies are divided into two categories as direct and indirect strategies. Under these categorization, memory, cognitive and compensation strategies are among the direct strategies while social, affective and metacognitive strategies are among the indirect strategies. Moreover, it is widely known that each strategy can be divided into more sub-strategies but in this study the strategy items that are related with remembering more effectively, using all mental processes, compensating for missing knowledge, organizing and evaluating learning, managing the emotions and leaning with others are under consideration.

\section{Attitudes towards Foreign Language Learning}

As Ellis (1994, p. 197-201) states there are many things that identifies the learners language competence as attitudes have been identified as one set of variables of major importance. The attitudes are shaped by the social factors such as age, gender, social class and ethnic identity which have different effects on learner outcome. This also means that these factors may cause both positive and negative attitudes towards the foreign or second language being learnt. The positive attitudes typically connect the speakers and learners of the language and its culture. Such positive attitudes can be accepted to enhance language learning because the learners are eager to be able to communicate with the native speakers of the target language. In fact, the more the learners are interested in the countries where the target language is spoken, the more motivated they would be to learn the language (Noels et al. 2003, p.36).

Negative attitudes, on the other hand, may hinder the learners from language learning since the learners may feel themselves uninterested in the language they learn or have difficulty with teacher or the speakers of the target language. Although these attitudes have negative effects on L2 learning, they may also have positive effects on L2 learning such as the learner may have strong desire to learn a language or they may struggle with their negative attitudes.

Consequently, the learners may have different attitudes and these attitudes may also affect them differently. Changing the learner's attitudes from negative to the positive ones should be one of the aims that the educators, teachers and practitioners should have during the learning and teaching process. This aspect makes the current study more important as it aims not only define the strategies and attitudes of the language learners but also make meaningful connections with one another by searching the answers of below questions:

(1) What are ELT preparatory class students' strategy profiles in language learning?

(2) What are ELT preparatory class students' attitudes towards foreign language learning?

(3) How related are the ELT preparatory class students' strategy profiles and attitudes towards foreign language learning?

\section{Method}

\section{Participants}

23 students from the English Language Teaching Department of Amasya University participated in this study in the Fall and Spring Semester of 2014-2015 Academic Year. The selection of the participants was done in random regardless of their gender and race. The students ranged in age from 15 to 16 , and 19 of the 23 students were female and 4 of them 
were male. The high number of female participants is accepted as normal due to the female students' natural inclination to English Language Teaching Department. All of the participants were studying at the preparatory level and they all got the main course, grammar, reading, writing, listening and speaking courses throughout the whole year.

\section{Instruments}

The data provide basis for this research have been collected via two different data collection instruments which are labelled as SILL (Strategy Inventory for Language Learning) and a questionnaire on attitudes towards learning a foreign language. The strategy inventory for Language Learning (SILL) is for the students of a second language developed by Oxford (1990). This inventory consists of 5 parts aimed to define the students strategy profiles in terms of remembering more effectively, using all mental process, compensating for missing, organizing and evaluating, managing emotions, learning with others. The inventory comprises 50 items each of which is labelled with the options that range from " $1=$ Never or almost never true for me", " 2 = Usually not true of me", " 3 = Somewhat true of me", " "4= Usually true of me" and " $5=$ Always or almost always true of me". The questionnaire on attitudes towards foreign language learning was adopted by Tunçok (2010) from Horwitz's (1988) Beliefs About Language Learning Inventory (BALLI) and the Attitude/ Motivation Test Battery (AMTB) by Gardner (1985) adding eight more items. The questionnaire consists of 31 items and the answers are labelled as 7 point likert-type format sequencing from 1(totally disagree) to 7 (totally agree).

\section{Data Collection}

The Strategy Inventory for Language Learning (SILL) was administered to 23 ELT preparatory class students of Amasya University at the end of the fall semester. Due to the fact that they are expected to fill the inventory during the semester break, the return rate from ELT preparatory class students was 23 . The questionnaire on attitudes towards foreign language learning was applied to the same students at the beginning of the spring semester. Although one of these students passed the preparatory class successfully in the in the middle of this academic year, this student also accepted to fill this questionnaire as well. In the process of filling the inventory and questionnaire, ELT preparatory class students were asked about their personal information concerning their age, gender, having preparatory class before and how many years they have been studying English. The gathered data was coded and analyzed via SPSS 17.00 package program for social sciences. Since time limitation, budget deficiency and restricted number of the students made it difficult for researcher to administer the inventory and questionnaire to a larger sample, the researcher made use of convenience sampling method in the present research. As the number of the participant is below 30, which is accepted as a limit number for parametric studies, in this study non-parametric methods, were applied to the gathered data. Apart from the number of the participants, the number of the items in the SILL (50 items) and in the questionnaire (31 items) make the data collection process more valid as well. 


\section{Findings and Results}

Table 5.1.: Reliability Coefficiencies of Data Collection Instruments

\begin{tabular}{lcc}
\hline Data Collection Instrument & $\begin{array}{c}\text { Number of } \\
\text { Items }\end{array}$ & Cronbach alfa $(\alpha)$ \\
\hline SILL & 50 &, 94 \\
Questionnaire & 31 &, 78 \\
\hline
\end{tabular}

When it is paid attention to the Cronbach alfa levels of the scales as calculated as .94 and .78, it claimed that the SILL and Attitude Questionnaire can be effectively used in this research since the reliability levels of these instruments are highly acceptable. Here, the researchers should keep in their mind this rule with caution:

\begin{tabular}{|c|c|}
\hline Cronbach's alpha & Internal consistency \\
\hline$\alpha \geq 0.9$ & Excellent (High-Stakes testing) \\
\hline $0.7 \leq \alpha<0.9$ & Good (Low-Stakes testing) \\
\hline $0.6 \leq \alpha<0.7$ & Acceptable \\
\hline $0.5 \leq \alpha<0.6$ & Poor \\
\hline$\alpha<0.5$ & Unacceptable \\
\hline
\end{tabular}

Table 5.2.: One-Sample T-Test Results for Sections of SILL

\begin{tabular}{lcccccc}
\hline \multicolumn{1}{c}{ Sections } & $\boldsymbol{N}$ & $\overline{\mathrm{X}}$ & $\boldsymbol{S}$ & $\boldsymbol{s d}$ & $\boldsymbol{T}$ & $\boldsymbol{p}$ \\
\hline Remembering more effectively & 23 & 3,372 &, 61282 & 22 & 26,38 &, 000 \\
Using all mental processes & 23 & 3,568 &, 66536 & & 25,72 &, 000 \\
Compensating for missing & 23 & 3,594 &, 57915 & & 29,76 &, 000 \\
Knowledge & & & & & & \\
Organising\&evaluating Learning & 23 & 3,676 &, 77337 & & 22,79 &, 000 \\
Managing Emotions & 23 & 3,079 &, 88459 & & 16,69 &, 000 \\
Learning with Others & 23 & 3,623 &, 76906 & & 22,59 &, 000 \\
\hline
\end{tabular}

As for the first research question of this study which refers the strategy profiles of ELT preparatory class students, in Table 5.2 One-Sample T-Test results of all sections of SILL are presented. According to the findings, the mean value of "remembering more effectively" was calculated as 3,37, "using all mental processes" was calculated as 3.56, "compensating for missing knowledge" and "organising\&evaluating learning" sections were calculated as 3.59 and 3.67 while "managing emotions" and "learning with others" were calculated as 3.07 and 3.62.

Figure 5.1. SILL Profile Results for Each Section

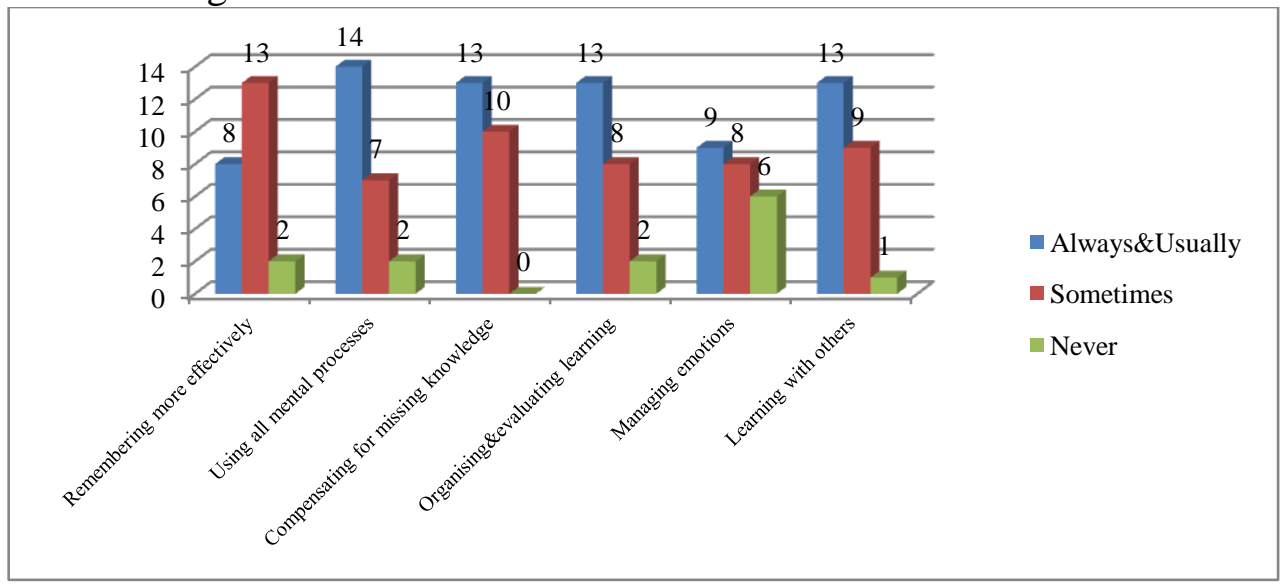


Figure 5.1. SILL Profile Results for Each Section explains the each section included in the inventory in terms of the ELT preparatory class students' answers. Thus, it clarifies the number of students who answers the items of inventory as always and usually, sometimes and never paying attention to the frequencies of the strategies they use while learning or using the language.

Figure 5.2. Overall Averages of SILL

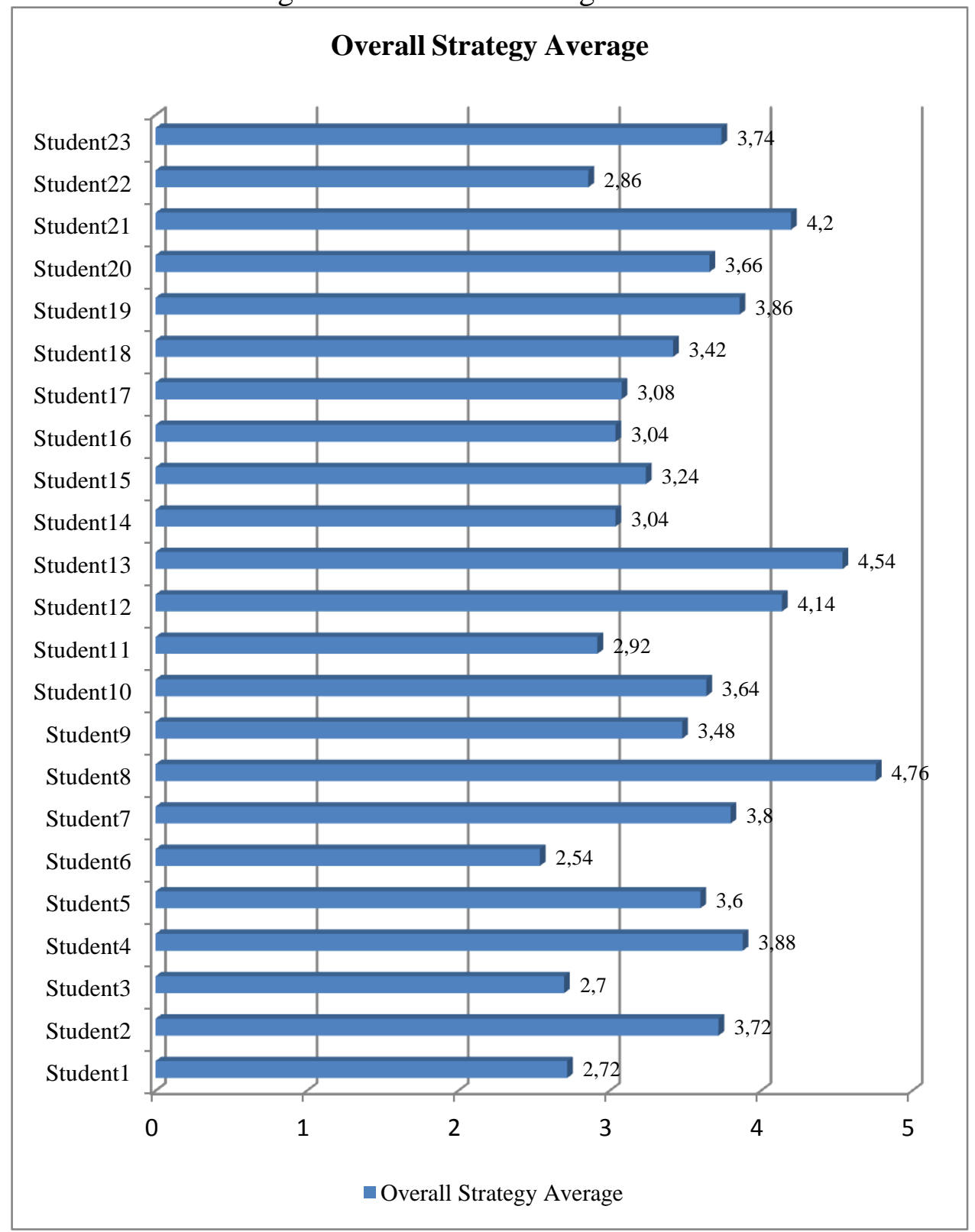

Figure 5.1. Overall Averages of SILL gives detail levels of each ELT preparatory class students' strategy level. As for the given values, it is observed that only four of them always use strategies while learning or using a language which underlines the importance of the strategy use in the process of language learning and teaching as well.

Table 5.3.: One-Sample T-Test Results for Sections of Attitudes Questionnaire

\begin{tabular}{|c|c|c|c|c|c|c|}
\hline Sections & $N$ & $\bar{X}$ & $S$ & $s d$ & $T$ & $p$ \\
\hline Cognitive Component & 23 & 5,181 & 1,232 & 22 & 19,71 & ,000 \\
\hline $\begin{array}{l}\text { Affective/ Evaluative Component } \\
\text { (Extrinsic Motivation) }\end{array}$ & 23 & 2,897 &, 7702 & & 17,64 & ,000 \\
\hline
\end{tabular}




\begin{tabular}{lccccc}
\hline $\begin{array}{l}\text { Affective/ Evaluative Component } \\
\text { (Intrinsic Motivation) }\end{array}$ & 23 & 5,621 & 1,019 & 25,85 &, 000 \\
$\begin{array}{l}\text { Affective/ Evaluative Component } \\
\text { (Teacher Influence) }\end{array}$ & 23 & 6,197 & 1,143 & 25,40 &, 000 \\
$\begin{array}{l}\text { Behavioral/Personality Component } \\
\text { (Inhibition) }\end{array}$ & 23 & 4,803 &, 9845 & 22,87 &, 000 \\
$\begin{array}{l}\text { Behavioral/Personality Component } \\
\text { (Exhibition) }\end{array}$ & 23 & 5,833 &, 9186 & $29,78,000$ \\
$\begin{array}{l}\text { Behavioral/Personality Component } \\
\text { (Tolerance of Ambiguity) }\end{array}$ & 23 & 3,484 & 1,087 & 15,03 &, 000 \\
$\begin{array}{l}\text { Behavioral/Personality Component } \\
\text { (Learning Effort) }\end{array}$ & 23 & 3,931 & 1,091 & 16,89 &, 000 \\
\hline
\end{tabular}

As for the second research question of this study which refers the attitudes of ELT preparatory class students towards a foreign language learning, in Table 5.3 One-Sample TTest results of all sections of Attitude Questionnaire are presented. According to the findings, the mean value of "Cognitive Component" and "Extrinsic Motivation"' were calculated as 5.18 and 2.89, "Intrinsic Motivation" and "Teacher Influence" were 5.62 and 6.19. Moreover, "Inhibition" and "Exhibition", were calculated as 4.80, 5.83 while "Tolerance of Ambiguity" and "Learning Effort" were calculated as 3.48 and 3.93.

Figure 5.3. Attitudes Profiles Results for Each Section

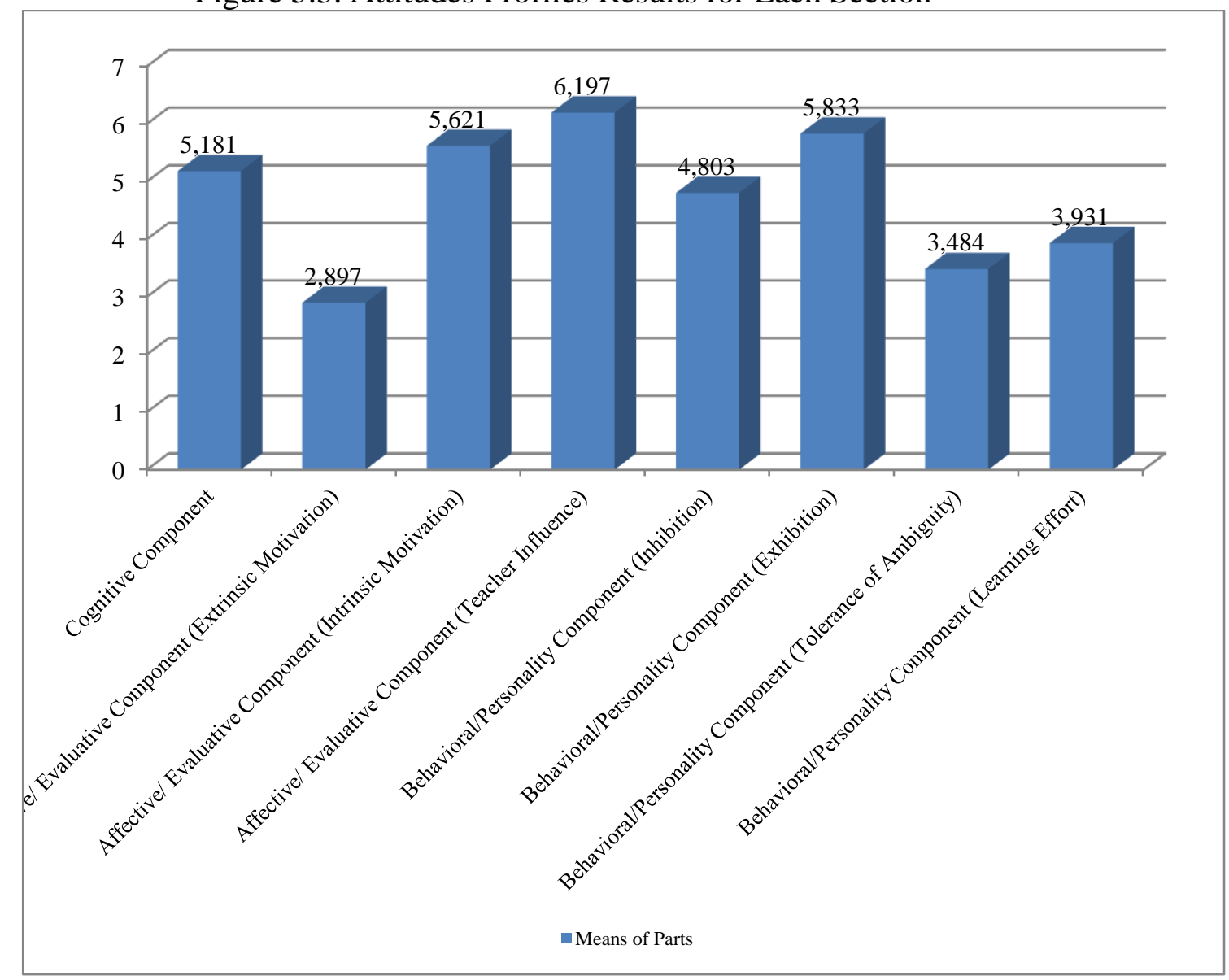


Figure 5.3. Attitudes Profiles Results for Each Section clarifies each section of Attitude Questionnaire since the ELT class students attitudes towards a foreign language are affected mostly by the teacher influence of affective component that is followed by exhibition of behavioral/personal component and intrinsic motivation of affective component again.

Figure 5.4. Overall Averages of Attitudes

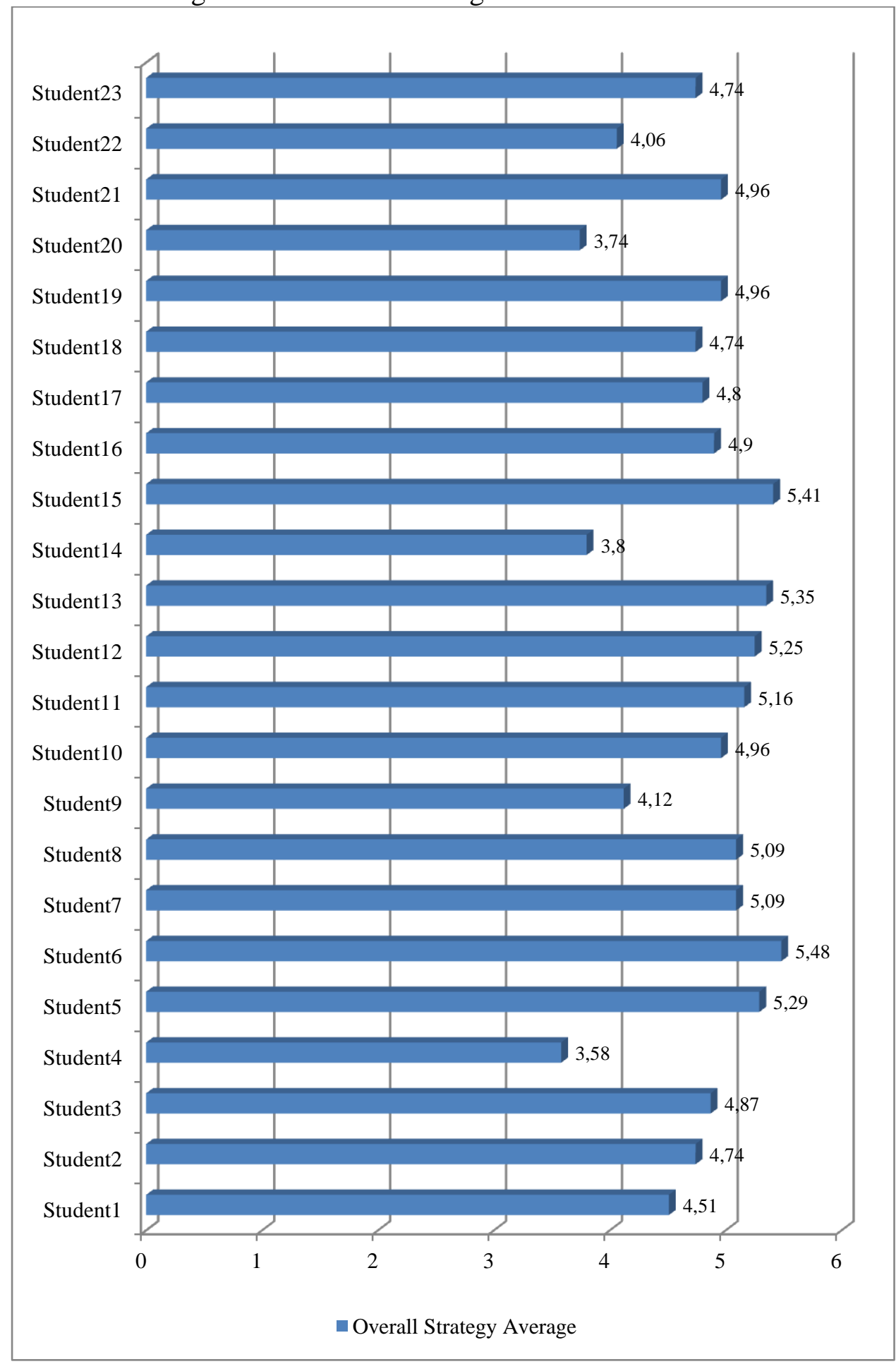


Figure 5.4. Overall Averages of Attitudes shows each ELT preparatory class student attitudes towards foreign language learning and summarizes that most of the students have positive attitudes towards language learning process.

Table 5.4. Descriptive Statistics of ANOVA Results of ELT Preparatory Class Students' Strategy and Attitude Levels

\begin{tabular}{lccr}
\hline Strategy and Attıtude & $\mathbf{N}$ & $\bar{X}$ & S \\
\hline Remembering more effectively & 23 & 3,3720 &, 612 \\
Using all mental processes & 23 & 3,5683 &, 665 \\
Compensating for missing knowledge & 23 & 3,5942 &, 579 \\
Organising\&evaluating learning & 23 & 3,6763 &, 773 \\
Managing emotions & 23 & 3,0797 &, 884 \\
Learning with others & 23 & 3,6232 &, 769 \\
Cognitive Component & 23 & 5,2435 & 1,24 \\
Affective/ Evaluative Component (Extrinsic Motivation) & 23 & 2,8804 &, 757 \\
Affective/ Evaluative Component (Intrinsic Motivation) & 23 & 5,6377 &, 999 \\
Affective/ Evaluative Component (Teacher Influence) & 23 & 6,2319 & 1,13 \\
Behavioral/Personality Component (Inhibition) & 23 & 4,7826 &, 967 \\
Behavioral/Personality Component (Exhibition) & 23 & 5,8841 &, 929 \\
Behavioral/Personality Component (Tolerance of Ambiguity) & 23 & 3,4493 & 1,07 \\
Behavioral/Personality Component (Learning Effort) & 23 & 3,8913 & 1,08 \\
\hline
\end{tabular}

In terms of the third research question which seeks the answer of how related the ELT preparatory class students' strategy profiles and attitudes towards foreign language learning are, Table 5.4 shares the descriptive result of ANOVA which is used to specify the strategy profiles and attitudes levels of ELT preparatory class students.

Table 5.5. One Way ANOVA Results for Repeated Features of ELT Preparatory Class Students' Strategy and Attitude Levels

\begin{tabular}{|c|c|c|c|c|c|c|}
\hline $\begin{array}{l}\text { Source of } \\
\text { Variation }\end{array}$ & $\begin{array}{l}\text { Sum of } \\
\text { Squares }\end{array}$ & Sd & Mean Squares & $\mathbf{F}$ & $\mathbf{p}$ & Significant Difference \\
\hline Between Subjects & 53,787 & 22 & 2,445 & 40,42 & .000 & $\begin{array}{l}1-7,1-9,1-10,1-11 \\
1-12,2-7,2-9,2-10 \\
2-11,2-12,3-7,3-9\end{array}$ \\
\hline Measure & 371,970 & 13 & 28,613 & & & $\begin{array}{l}3-10,3-11,3-12,4-5 \\
4-7,4-9,4-10,4-11\end{array}$ \\
\hline Error & 202,428 & 286 & ,708 & & & $\begin{array}{l}4-12,5-7,5-9,5-10, \\
5-11,5-12,6-7,6-9, \\
6-10,6-11,6-12,7-8, \\
7-13,7-14,8-7,8-9, \\
8-10,8-11,8-12,9-13, \\
9-14,10-11,10-13, \\
10-14,11-13,12-13, \\
12-14\end{array}$ \\
\hline Total & 628,185 & 321 & 31,766 & & & \\
\hline
\end{tabular}

Table 5.5. One Way ANOVA Results for Repeated Features of ELT Preparatory Class Students' Strategy and Attitude Levels figures out 14 factors relationship with each other and whether there is significance difference between the factors or not. As a result, the factors that have significance difference are presented in the above table by indicating the other factors may have positive relationship with each other in the process of language learning.

\section{Conclusion and Recommendations}

The present study investigates the strategy profiles and attitudes of ELT preparatory class students at Amasya University. The results of the study reveals that although language 
learning process is directly related to the individual strategy use of learners, most of the ELT preparatory class students usually use the strategies during their language learning process. This result underlines the importance of strategy use throughout the process of language learning and teaching not only by the learners themselves but also the educators, practitioners, teachers or who takes the responsibility to convey the process of teaching a language should also perform their responsibilities and encourage their students or learners to use the language learning strategies more effectively than they do.

Another important result of this study that should be paid attention is the ELT preparatory class students' attitudes towards learning a foreign language. In the present study, the results indicate that learners are under the influence of affective and evaluative components rather than the other ones. Here, this study emphasizes the importance of teacher influence and intrinsic motivation besides exhibition that is also a behavioural and personality component. Therefore, during the foreign language teaching and learning process the policy makers and who are under the service of these responsible people should plan the whole process in accordance to the learners' attitudes towards learning a foreign language. Parallel to this findings, in-service or pre-service training and developments may be organized to reach better learning and teaching conditions.

Moreover, the relationship between the learners strategy profiles and their attitudes towards a foreign language learning should not be ignored. Since the learners strategies and attitudes are more interrelated with each other due to being different factors that shape the foreign language learning process of learners universally. That is why the researchers should evaluate the process of learning a language by keeping in mind the importance of different aspects of learning and teaching that have high possibility to affect the whole process. In addition, this small scale study of 23 ELT preparatory class students could be repeated with more participants including a control group to generalize the findings. This point could be the topic of another study and shed light on further studies.

\section{References}

Brown, H. D. (2000). Principles of language learning and teaching (4th ed.). New York: Longman.

Ellis, R.(1994). The study of second language acquisition. Oxford: Oxford University Press.

Ellis, R.(1997). Second Language Acquisition. Oxford: Oxford University Press.

Gan, Z. (2004). Attitudes and strategies as predictors of self-directed language learning in an EFL context. International Journal of Applied Linguistics, 14, 389- 411.

Gardner, R. C. (1985). Social psychology and second language learning: The role of attitudes and motivation. London: Edward

Guilloteaux, M. J. \& Dörnyei, Z. (2009). Reply to Rod Ellis "es comment on "Motivating language learners: A classroom-oriented investigation of the effects of motivational strategies on student motivation". TESOL Quarterly, 43(1), 109-111.

Horwitz, E. K. (1998). The beliefs about language learning of beginning university foreign language students. Modern Language Journal, 72(3), 283-294.

Noels Kimberly A., Pelletier Luc G., Clément Richard \& Vallerand Robert J.(2003). Why Are You Learning a Second Language? Motivational Orientations and Self-Determination Theory. Language Learning, Vol. 53, No.S1:33-64.

Nunan, D. (1999). Second language teaching \& learning. Boston: Heinle \& Heinle Publishers. 
Oppenheim, A. N. (1993). Quesionnaire design, interviewing and attitude measurement. London: Pinter Publishers.

Towell, R. \& Hawkins, R. (1994). Approaches to second language acquisition. Clevedon: Longman Press. 